\title{
Development of a Hybrid Pin Joint with a Compressed Wooden Dowel and Metal Pipe
}

\author{
Kiho Jung, Shunpei Nakamine \\ Faculty of Education, Shizuoka University, Shizuoka, Japan \\ Email: ekjung@ipc.shizuoka.ac.jp
}

Received 14 February 2015; accepted 2 March 2015; published 3 March 2015

Copyright (C) 2015 by authors and Scientific Research Publishing Inc.

This work is licensed under the Creative Commons Attribution International License (CC BY). http://creativecommons.org/licenses/by/4.0/

cC) (i) Open Access

\begin{abstract}
A newly developed hybrid pin (HP), composed of a compressed wooden dowel inserted into a stainless steel pipe is suggested in this research. This configuration is expected to grant high stiffness by bending performance of the metal pipe and rich ductility through shear deformation of compressed wooden dowel without brittle split of the joint member. Experimental tests were performed in order to verify your assumptions and pursue an optimum design. Double shear test perpendicular to the grain of HP was conducted with parameter of thickness and loading direction for base member for pin's diameter. Rotational test for mortise and tenon joint inserted with HP was performed in order to evaluate the moment resisting performance. Consequently, the hybrid pin showed satisfactory performance as shear type fastener by virtues of not only relatively high stiffness but also rich ductility originated from the properties of each component, stain less steel pipe and compressed wood.
\end{abstract}

\section{Keywords}

Hybrid Pin, Compressed Wooden Dowel, Double Shear, Moment Resisting Performance

\section{Introduction}

In order to resist the destructive forces of earthquakes in Japanese small scale timber structures, structural performance (as eismic performance) is demanded. Timber structures have relatively low joint-performance compared to that of RC (reinforced concrete) or steel structures, and focus needs to be set not only stiffness but also on their ductility.

Consequently, various types of joints and a lot of effort have been put into improving the joint performance of a traditional wood-to-wood joint in order to apply it in modern joints using steel fasteners.

Recently, the new types of timber joint with less steel usage, and more newly developed materials have been 
vigorously introduced as improvement based on environmental points of view.

Hence, this research is focused on a shear-key type of joint. The shear-key type of joint has been widely used in traditional as well as in modern joinery until now due to its ease of assembly and relatively high performance as a mechanical joint method [1] [2]. In this type of joints, key fastener has a very important role because of its bending, compressive and shearing capacity, which highly influences the joint's performance.

Aiming to improve the key-joint's performance, a hybrid pin (HP), composed of a compressed wooden dowel [3] [4] inserted in a stainless steel pipe is suggested in this research.

Firstly, double shear perpendicular to the grain of HP was studied; focusing on the balance between shear performance and the ratio of base member' thickness for dowel's diameter [5]. Then, moment-resisting performance of mortise and tenon joint type with a HP was evaluated [6] [7].

\section{Material Property of HP}

\subsection{Characteristic of Material}

In this research, the hybrid pin is composed of a $12 \mathrm{~mm}$ inner-diameter stainless steel pipe (SUS304) with a thickness of $1 \mathrm{~mm}$, and a $12 \mathrm{~mm}$ diameter dowel of Japanese cedar (Cryptomeria japonica D. Don) compressed until $70 \%$ of its original radial dimension. The appearance of the hybrid pin is shown in Figure 1, and the stress distribution and reinforcing mechanism for the bending property is shown in Figure 2.

\subsection{Bending Properties}

The bending property for HP was obtained using the 3_Point bending test with $200 \mathrm{~mm}$ span as shown in Figure 3 . The cross-head's speed was $2 \mathrm{~mm} / \mathrm{min}$. One of the experiment's parameters was the loading direction in relation to the specimen's radial direction, which was set to $0^{\circ}$ (SC0) and $90^{\circ}$ (SC90) as shown in Figure 4.

Table 1 shows average values of modulus of rupture (MOR) and modulus of elasticity (MOE) for 3 tested specimens.

\subsection{Double Shear Property}

This section deals with the evaluation of double shear properties of HP focusing on the balance between strength, loading direction, and dimensions of the base member. The experimental results are then compared with the values calculated by European yield theory.

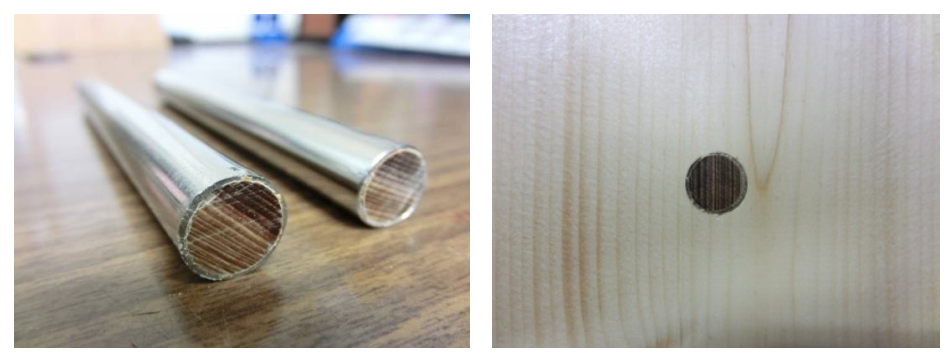

Figure 1. Shape of hybrid pin.

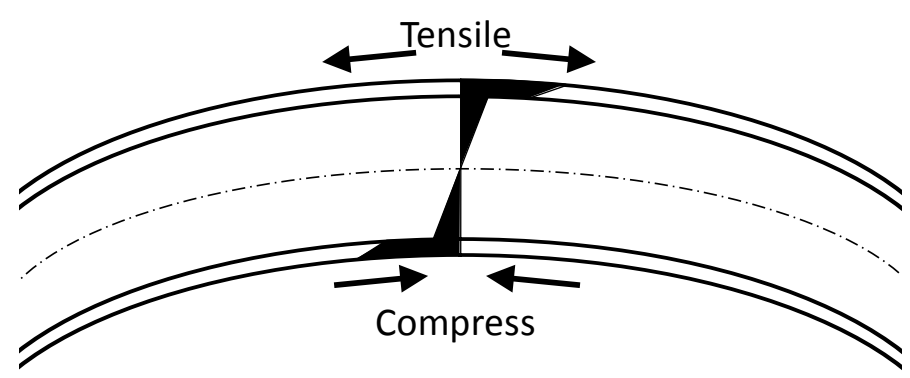

Figure 2. Stress distribution on HP on bending. 


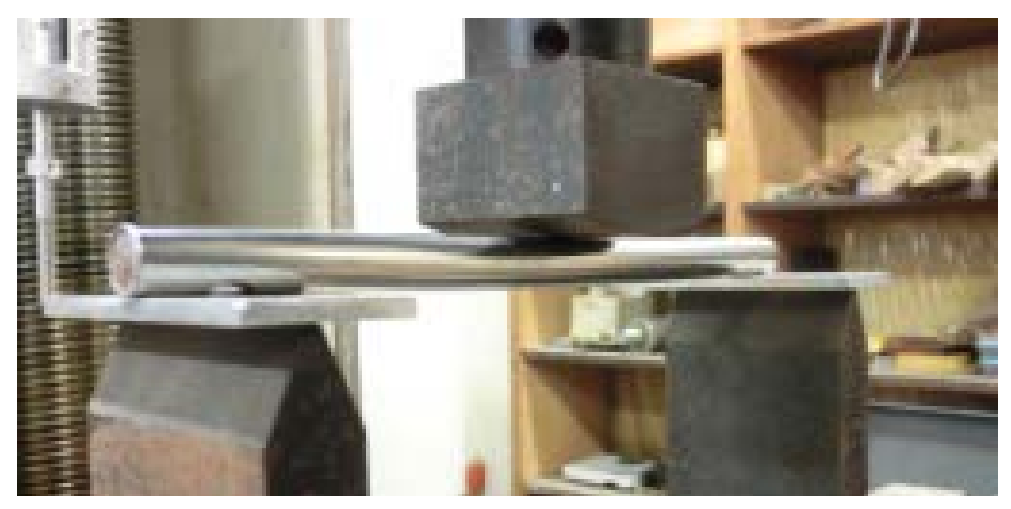

Figure 3. Bending test.

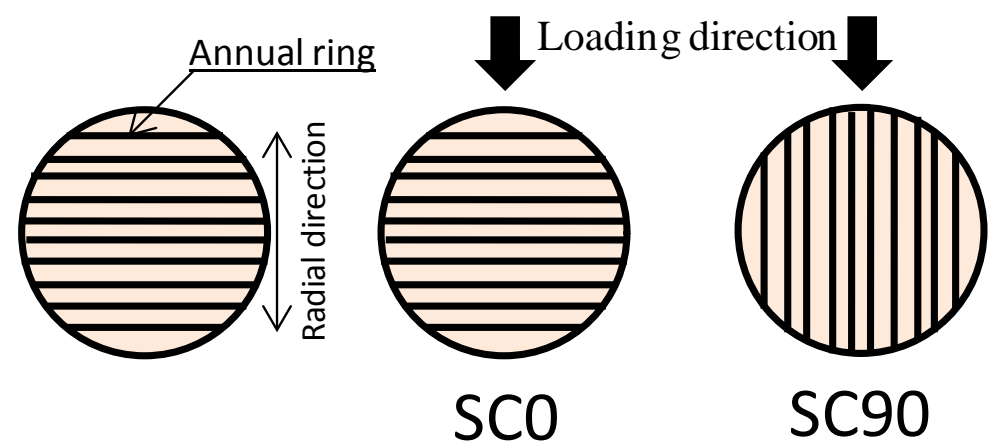

Figure 4. Loading direction for HP on bending test.

Table 1. Results of bending test.

\begin{tabular}{ccc}
\hline & Bending properties \\
\cline { 3 - 3 } & MOR (MPa) & MOE (GPa) \\
SC0 & 405 & 1352 \\
SC90 & 412 & 1462 \\
\hline
\end{tabular}

\subsubsection{Loading Direction Parallel to the Grain of the Base Member}

Double shear test of HP-joint with the loading direction parallel to the grain was performed in order to evaluate the performance of HP as shear-key fastener and verify its optimum design.

Four types of base members were prepared, with thicknesses of 1d (13 mm), 2d (26 mm), 3d (39 mm) and 4d (52 mm) for dowel diameter. Joints for double shear test were assembled to m2s1, m3s2, m4s3 as shown in Figure 5 and Table 2. The inserting direction of HP into the base member is defined relative to the loading direction, parallel to the radial direction of dowel (SC0) and perpendicular to the radial direction (SC90) as shown in Figure 6.

An axial load was applied by a testing machine (TCM10000: shinkoh) to each specimen to produce shear deformation between the main member and two side members of the test specimen, as shown in Figure 7.

Average relative shear deformation between the main and the side members was measured while the load was applied at a speed of $2 \mathrm{~mm} / \mathrm{min}$.

Figure 8 and Figure 9 show the relationship between load- and shear-deformation for each parameter of double shear test. Table 3 displays values of stiffness, yield, and maximum strength.

All the parameters show rich ductility after yielding. Yield and maximum strength increased with the thickness of the base member, although no considerable difference was found in the stiffness with variation of the 

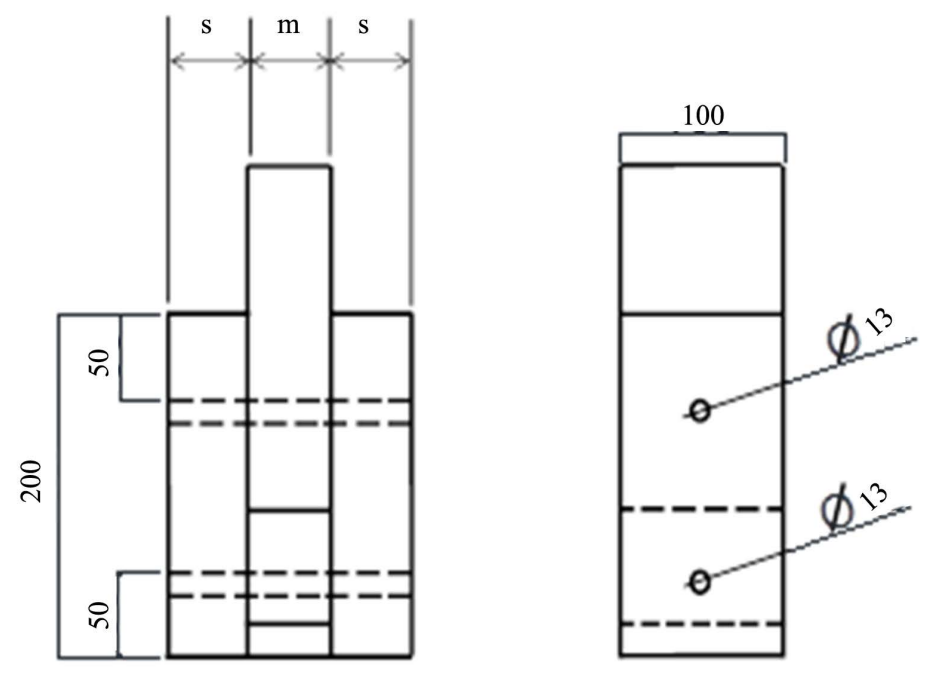

Figure 5. Specimen for double shear test parallel for loading direction parallel to the grain of the side member.
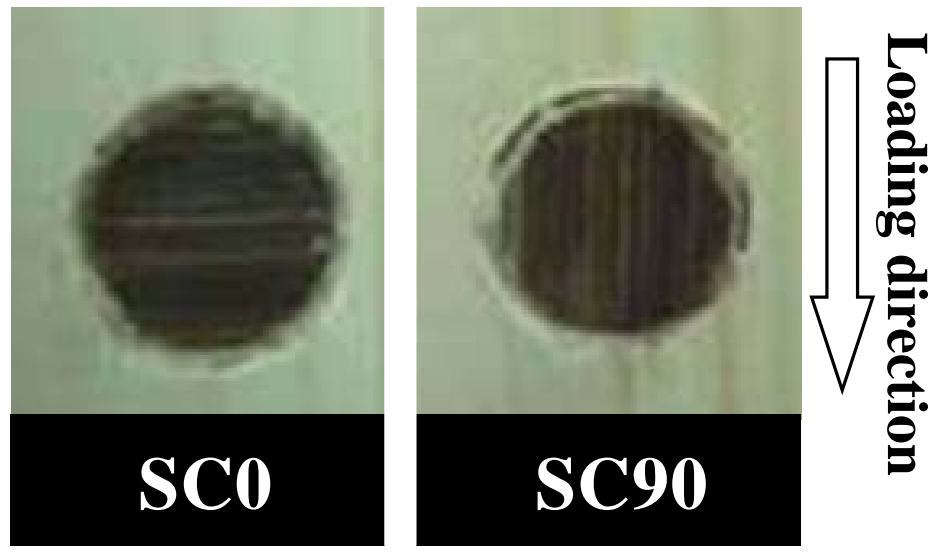

Figure 6. Inserting direction of HP.

Table 2. Size of base members.

\begin{tabular}{|c|c|c|c|c|c|}
\hline Base member & $\mathrm{L}(\mathrm{mm})$ & $\mathrm{W}(\mathrm{mm})$ & & $\mathrm{T}(\mathrm{mm}$ & \\
\hline \multirow{2}{*}{ Main member } & \multirow{2}{*}{200} & \multirow{2}{*}{100} & $\mathrm{~m} 2$ & $\mathrm{~m} 3$ & $\mathrm{~m} 4$ \\
\hline & & & 26 & 39 & 52 \\
\hline \multirow{2}{*}{ Side member } & \multirow{2}{*}{200} & \multirow{2}{*}{100} & $\mathrm{~S} 1$ & S2 & S3 \\
\hline & & & 12 & 26 & 39 \\
\hline
\end{tabular}

base member's thickness. Double shear performances improved with the thickness of the base member. But there is no big difference was observed regarding the inserting direction of the dowel.

Figure 10 shows deformed shape of each pin after double shear test for each setup. There is mode-I for setups m2s1, and mode-II for setup 2 for m3s2 and m4s3 by European yield theory [8]. Table 4 shows a comparison between experimental results and those calculated by EYT.

\subsubsection{Loading Direction Perpendicular to the Grain of the Base Member}

Double shear test of HP-joint with loading direction perpendicular to the grain of the base member was per- 
formed in order to evaluate the performance of HP as shear-key fastener, as shown in Figure 11.

The test specimen's thickness was cut to $3 \mathrm{~d}(39 \mathrm{~mm})$ for the main member and $2 \mathrm{~d}(26 \mathrm{~mm})$ for the side member. A $13 \mathrm{~mm}$ HP was used, as shown in Figure 12. The length of side member was 2.5 times (500 mm) the width of the main member.

Table 3. Results from double shear test. The loading direction case: parallel to the grain of the side member for loading direction on base member.

\begin{tabular}{|c|c|c|c|c|}
\hline \multirow{2}{*}{\multicolumn{2}{|c|}{ No. }} & Stiffness & Yield strength & Maximum strength \\
\hline & & $K(\mathrm{kgf} / \mathrm{mm})$ & $P_{\mathrm{y}}(\mathrm{kgf})$ & $P_{\max }(\mathrm{kgf})$ \\
\hline \multirow{4}{*}{$\mathrm{sC} 0 \mathrm{~m} 2 \mathrm{~s} 1$} & 1 & 849 & 741 & 911 \\
\hline & 2 & 1068 & 543 & 794 \\
\hline & 3 & 1065 & 527 & 928 \\
\hline & Ave. & 994 & 604 & 878 \\
\hline \multirow{5}{*}{$\mathrm{sC} 0 \mathrm{~m} 3 \mathrm{~s} 2$} & 1 & 1059 & 1161 & 1334 \\
\hline & 2 & 1071 & 928 & 1271 \\
\hline & & & & \\
\hline & 3 & 1150 & 1003 & 1304 \\
\hline & Ave. & 1093 & 1031 & 1303 \\
\hline \multirow{4}{*}{$\mathrm{sC} 0 \mathrm{~m} 4 \mathrm{~s} 3$} & 1 & 1061 & 894 & 1415 \\
\hline & 2 & 875 & 1054 & 1396 \\
\hline & 3 & 984 & 1145 & 1589 \\
\hline & Ave. & 973 & 1031 & 1467 \\
\hline \multirow{4}{*}{ sC90m2s1 } & 1 & 1210 & 789 & 871 \\
\hline & 2 & 1667 & 594 & 928 \\
\hline & 3 & 1703 & 577 & 911 \\
\hline & Ave. & 1527 & 653 & 904 \\
\hline \multirow{4}{*}{ SC90m3s2 } & 1 & 1470 & 953 & 1237 \\
\hline & 2 & 1966 & 853 & 1329 \\
\hline & 3 & 1413 & 978 & 1329 \\
\hline & Ave. & 1616 & 928 & 1299 \\
\hline \multirow{4}{*}{ sC90m4s3 } & 1 & 1121 & 897 & 1394 \\
\hline & 2 & 1092 & 1079 & 1405 \\
\hline & 3 & 1444 & 1137 & 1488 \\
\hline & Ave. & 1219 & 1038 & 1429 \\
\hline
\end{tabular}


Table 4. Comparison between values calculated by EYT and experimental results.

\begin{tabular}{ccc}
\hline & Experimental & EYT \\
\cline { 2 - 3 } No. & $P_{\text {y-exp }}(\mathrm{kgf})$ & $P_{\text {y-cal }}(\mathrm{kgf})$ \\
\hline SC0m2s1 & 604 & 878 \\
SC0m3s2 & 1031 & 1015 \\
SC0m4s3 & 1031 & 1522 \\
SC90m2s1 & 653 & 878 \\
SC90m3s2 & 928 & 1015 \\
SC90m4s3 & 1038 & 1522 \\
\hline
\end{tabular}

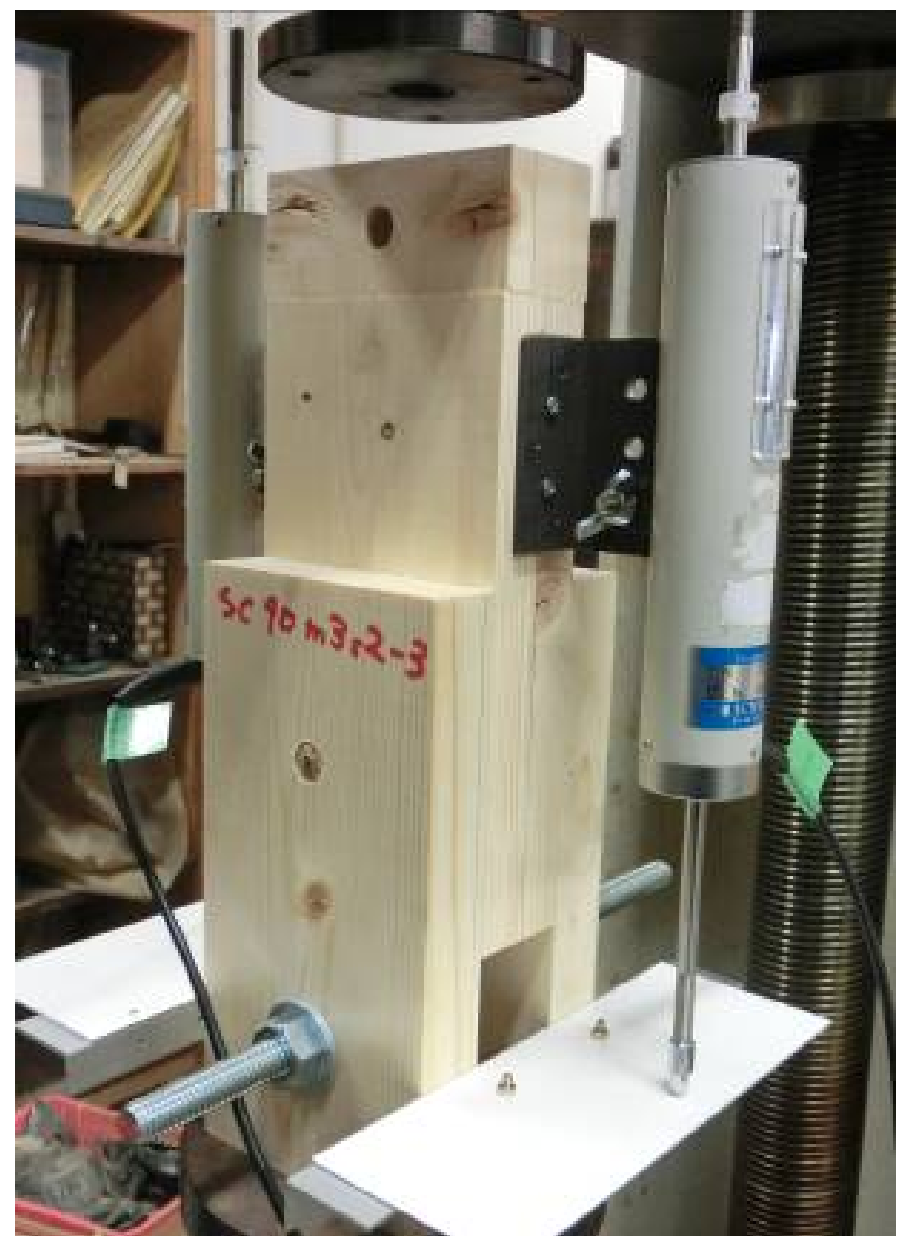

Figure 7. Double shear test setup, with load applied in direction parallel to the grain of the side member.

The test setup was placed on a 3-point bending test device with a $400 \mathrm{~mm}$-span in order to load the side members. Axial load was then applied to the main member at its center point. Shear deformation between main and side members was measured by displacement meter.

One specimen was tested by constant loading. Then yield strength was defined at $800 \mathrm{kgf}$. Thus the cyclic loading schedule was set to 100, 200, 400 and $800 \mathrm{kgf}$ for the other three specimens. After reaching the target load, the loading was decreased to 0 kgf then next target load was then followed. The cyclic loading test was 
finished once the last target load of 800 kgf was reached. Subsequently, a constant load was applied until the specimen's failure or drop of load to an $80 \%$ of the maximum load. The loading speed was $0.5 \mathrm{~mm} / \mathrm{min}$ for cyclic loading test and $3 \mathrm{~mm} / \mathrm{min}$ for the constant loading test.
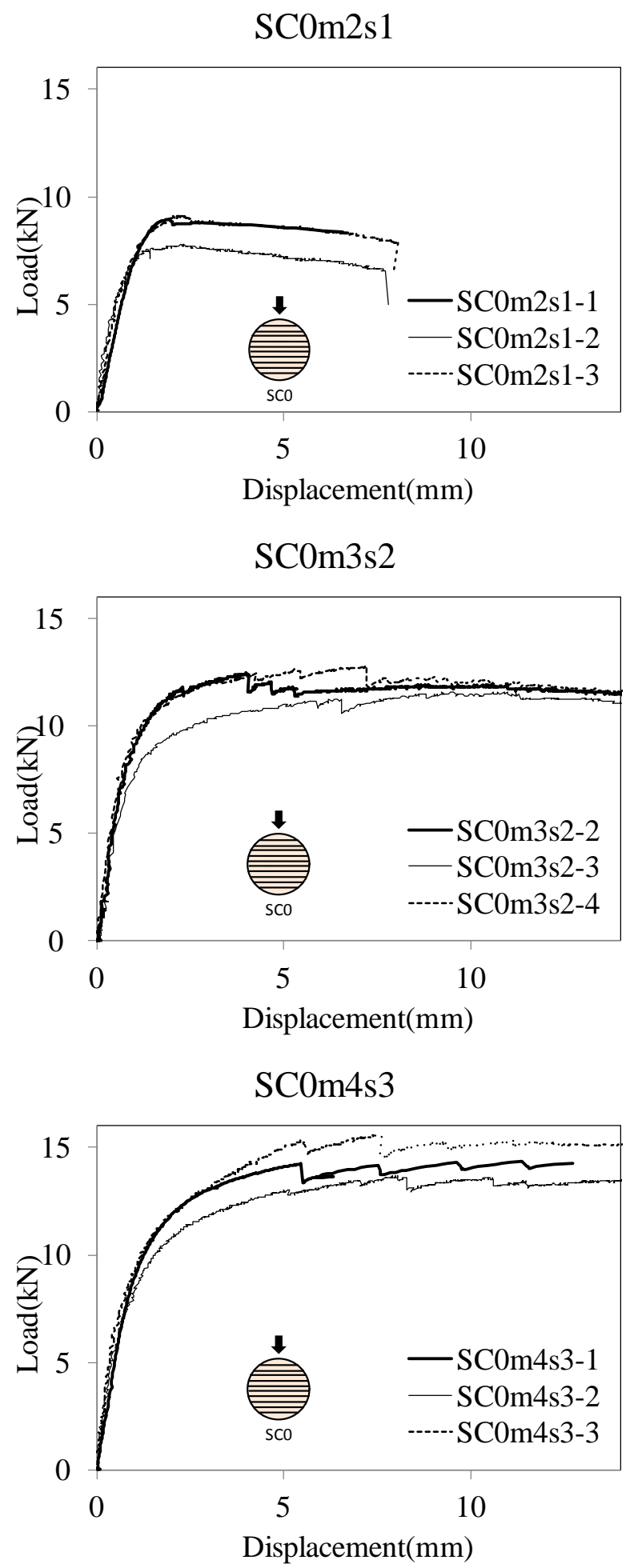

Figure 8. Relationship between load and deformation on loading direction parallel to radial direction of dowel. 

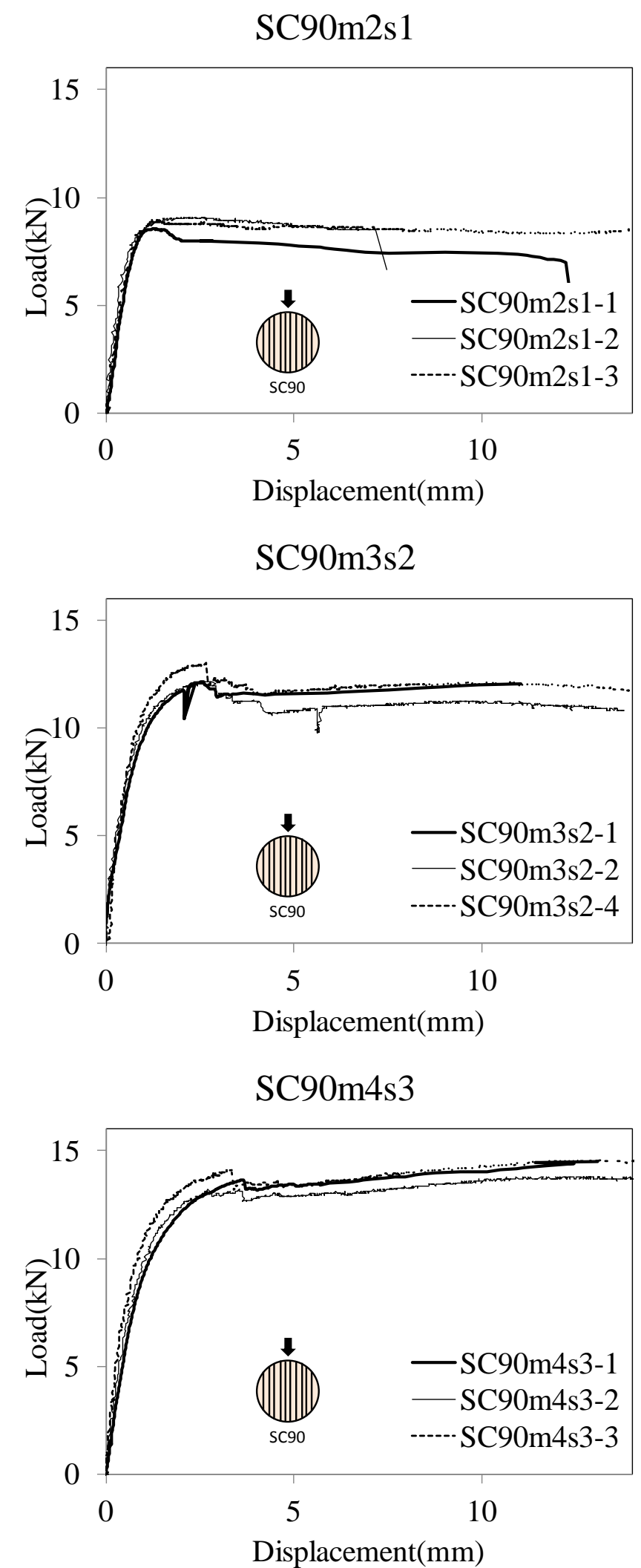

Figure 9. Relationship between load and deformation on loading direction perpendicular to radial direction of dowel. 


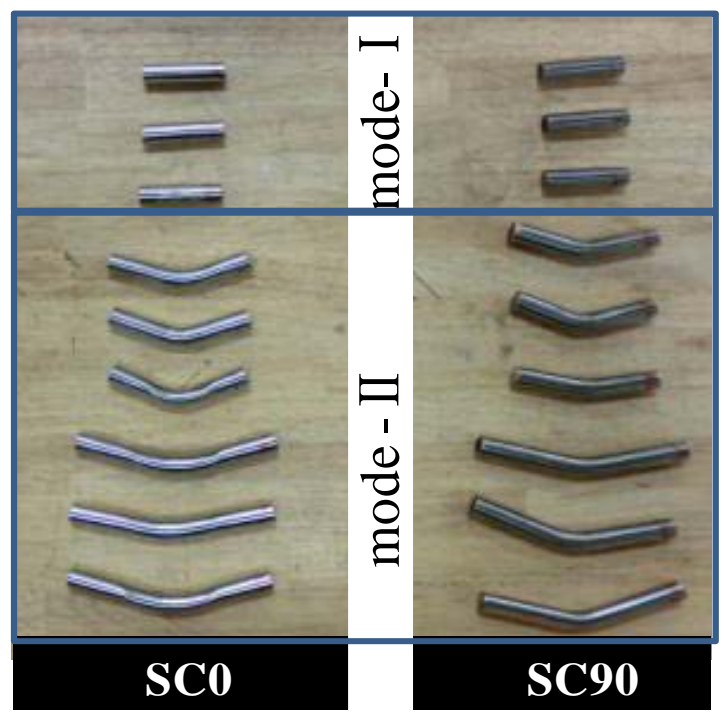

Figure 10. Shape of HP after double shear test.

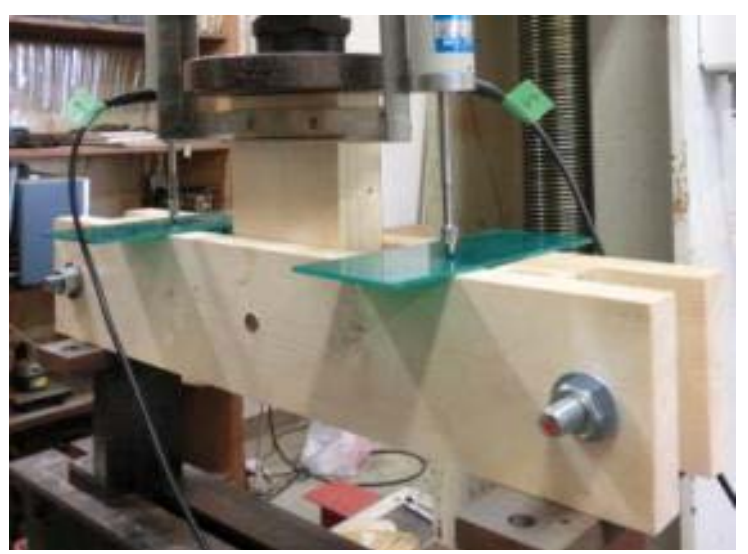

Figure 11. Setup of double shear test with the loading direction perpendicular to the grain of side member.

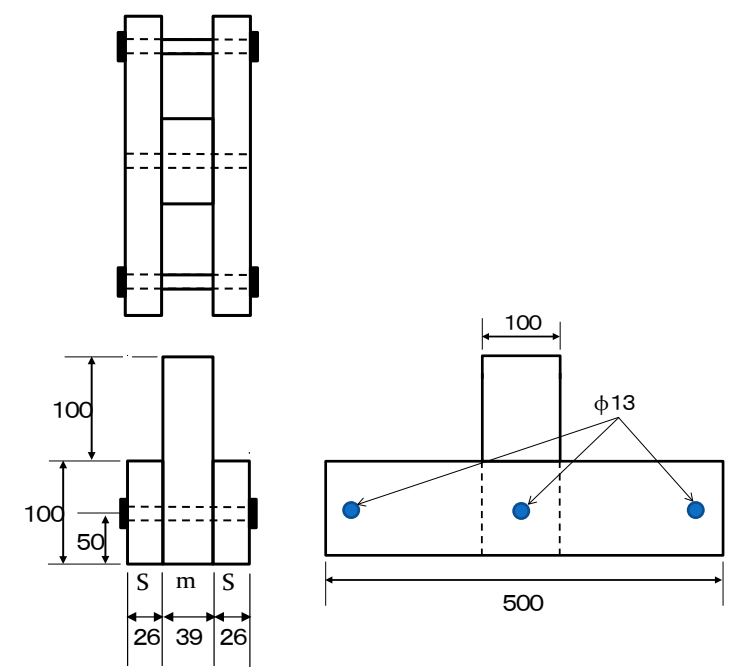

Figure 12. Specimen for double shear test, loading direction perpendicular to the grain of side member. 
Figure 13 shows load-displacement curves of each type of HP. Table 5 shows the results from double shear test with the specimen loaded in the direction perpendicular to the grain of the side member. The specimen type $\mathrm{m} 3 \mathrm{~s} 2$ showed a stiffness of $680 \mathrm{kgf} / \mathrm{mm}$, and a yield strength of $840 \mathrm{kgf}$.

Even though a joint with a steel pin resulted in a 2.5 times higher stiffness, and 1.4 times higher maximum strength than a HP-joint but brittlely failed soon after reaching maximum strength.

However, HP-joint showed idealistic performance that it had long plastic zone maintaining almost same level of maximum strength after yielding from $3 \mathrm{~mm}$ to $20 \mathrm{~mm}$ in displacement. HP-joint showed 3 times than steel pin joint in energy consumption.

No significant differences between constant loading and repeated loading were revealed from the double shear test performed on HP-joint. Figure 14 shows displacement-load in repeated loading test scheduled.

Shear performance of loading direction perpendicular to the grain of the base member in side member is lower than that of parallel in chapter 2.3.1. It is due to bearing strength of perpendicular to the grain of the base member is relatively lower than that of parallel direction.

\section{Rotational Test on HP-Joint}

Moment resisting joint using HP was suggested. Figure 15 shows each type of specimen with different configu-

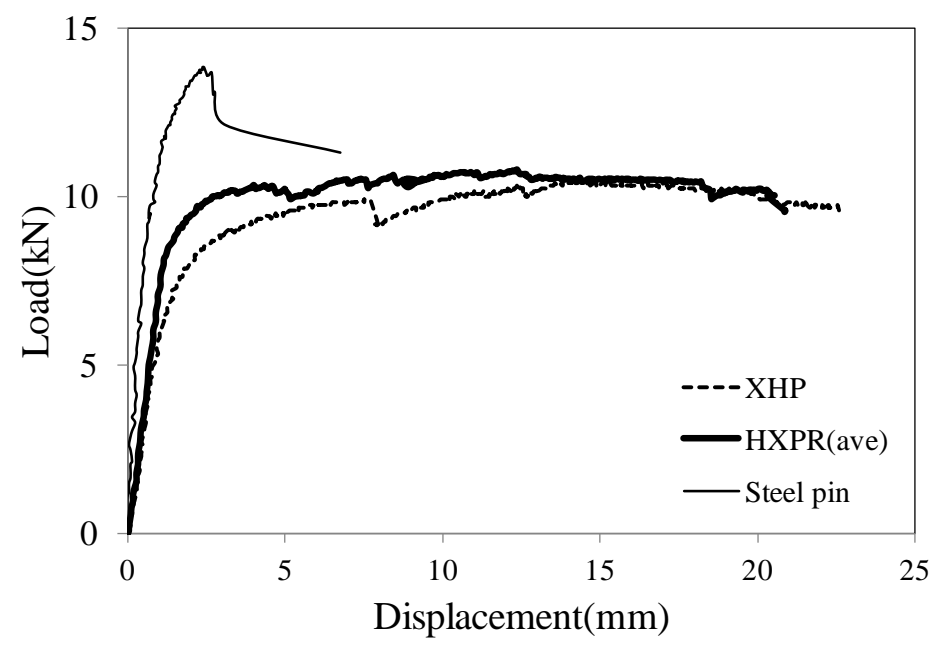

Figure 13. Comparison of double shear performance (XHP: constant loaded specimen, XHPR: repeated loaded specimen, $12 \mathrm{~mm} \mathrm{HP}$ ).

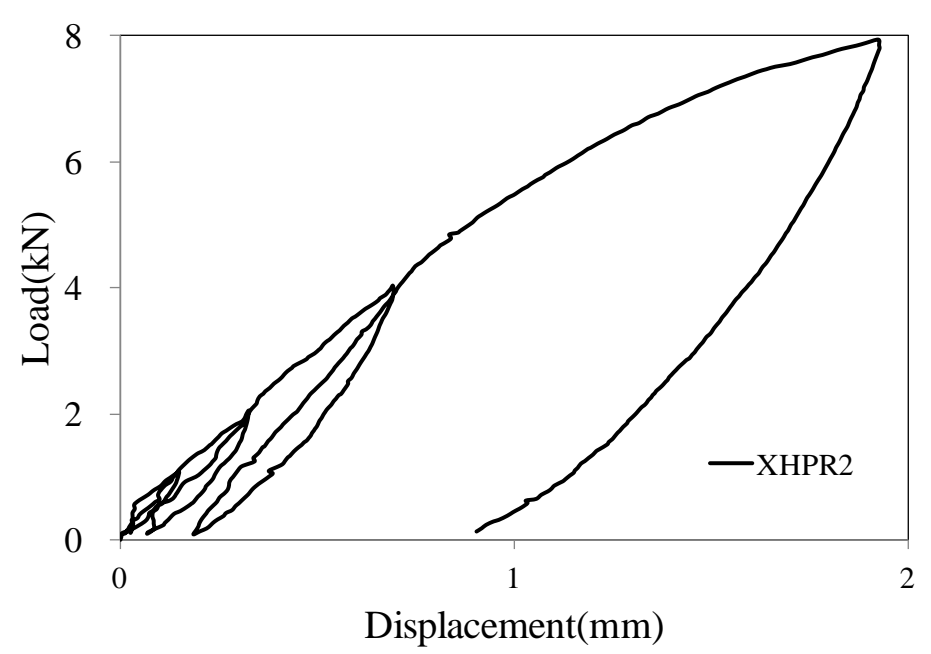

Figure 14. Repeated loading test on XHPR2. 
Table 5. Results of double shear test perpendicular to the grain of side member for loading direction.

\begin{tabular}{cccccccc}
\hline & \multicolumn{3}{c}{ Constant loading } & \multicolumn{3}{c}{ Repeated loading } \\
\cline { 2 - 7 } & XHP & Steel pin & XHPR1 & XHPR2 & XHPR3 & Ave. \\
\hline$K(\mathrm{kN} / \mathrm{mm})$ & 3.94 & 15.74 & 4.60 & 6.89 & 8.39 & $\mathbf{6 . 6 3}$ \\
$P_{\mathrm{y}}(\mathrm{kN})$ & 7.78 & 9.59 & 8.60 & 8.19 & 7.87 & $\mathbf{8 . 2 2}$ \\
$P_{\max }(\mathrm{kN})$ & 10.49 & 13.85 & 10.98 & 10.73 & 10.73 & $\mathbf{1 0 . 8 2}$ \\
$E(\mathrm{kNmm})$ & 223 & 76 & 220 & 310 & 211 & $\mathbf{2 4 7}$ \\
\hline
\end{tabular}

Note: $K$ : initial stiffness, $P_{\mathrm{y}}$ : yield strength, $P_{\max }$ : maximum strength, $E$ : energy.
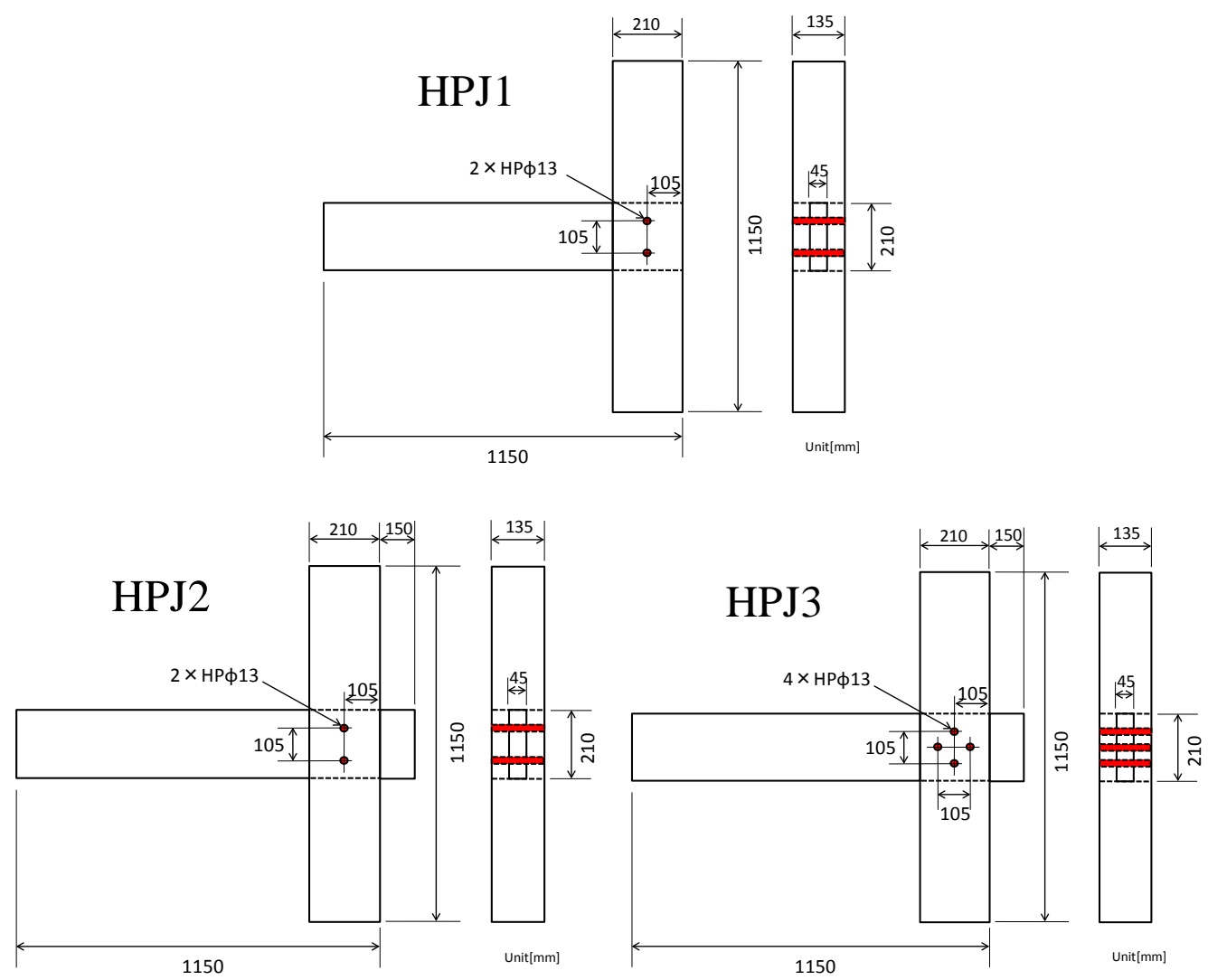

Figure 15. Each type of HP-Joint.

ration for the dowel's insertion. The specimen was made of spruce (Piceaabies) glue-lam. The jointing process, involved the manufacturing of mortise-and-tenon on each specimen, their assembling, drilling of holes, and insertion of HP. Each specimen was placed on a frame with hydraulically-operated jack, as shown in Figure 16. In order to give rotational moment to the joint, the beam was fixed with a long metal arm and each of the 3 hinges was fixed by a $16 \mathrm{~mm}$-diameter steel pin.

Horizontal load was applied by hydraulically controlled Jack at the top of the column. The applied load, and horizontal displacement were simultaneously measured.

A cyclic loading schedule was applied as follows: $\pm 1 / 300,1 / 150,1 / 75,1 / 50,1 / 25,1 / 10$ (Rad) at a first step, afterwards a constant loading was applied until to the specimen's failure or limited displacement at test machine. Figure 17 shows the details of the loading during the test.

Figure 18 shows moment vs. rotational angle of each type of specimens. Table 6 displays values of stiffness, yield moment, maximum moment, and energy from rotational test. On the different length of mortise with same 


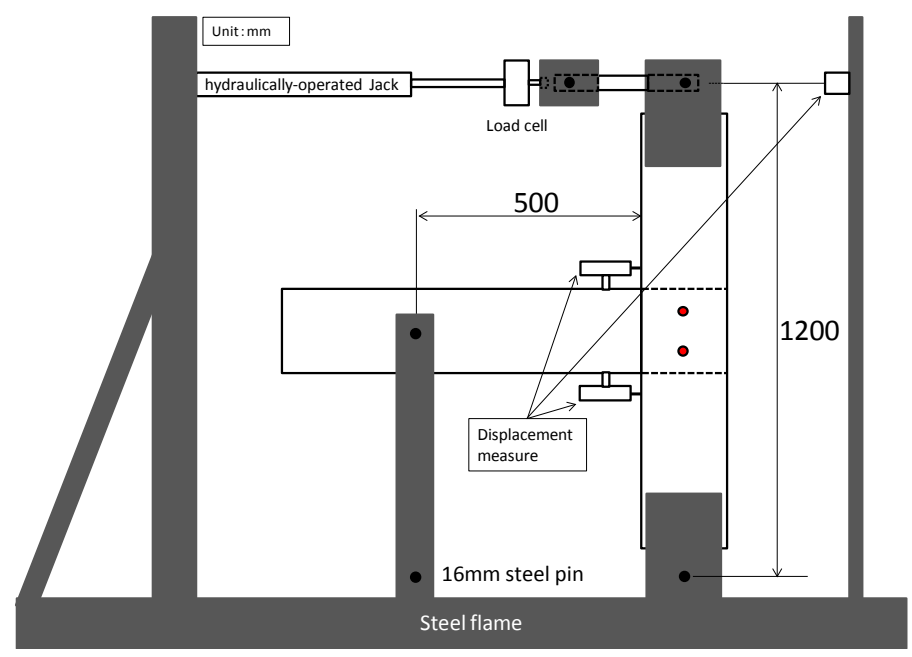

Figure 16. Setup for rotational test.

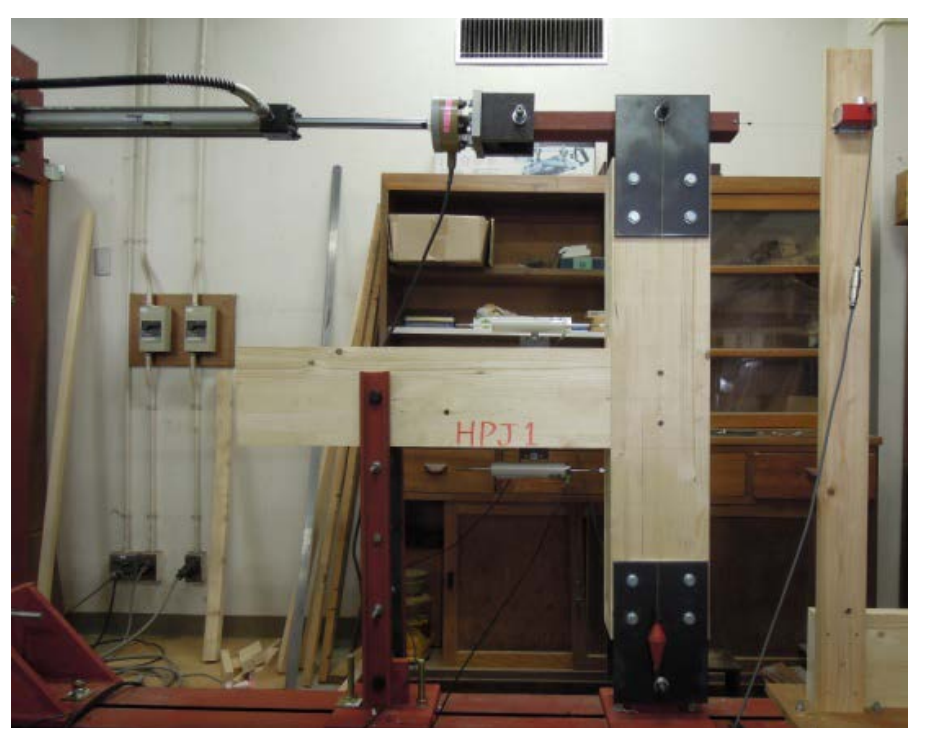

Figure 17. Rotational test for HP joint.

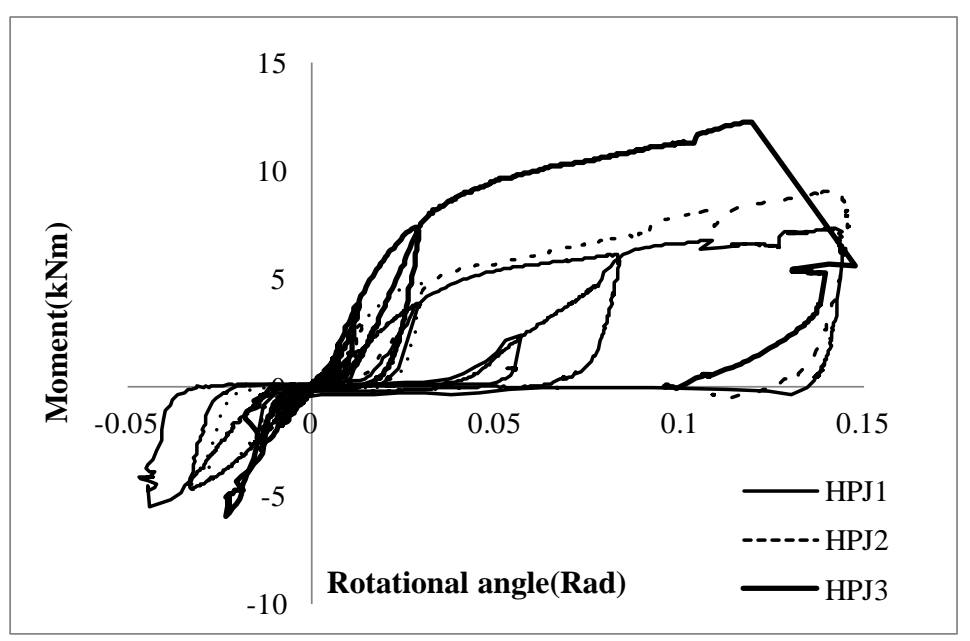

Figure 18. Moment (kNm) vs. rotational angle. 
Table 6. Results from the rotational test.

\begin{tabular}{ccccc}
\hline & Stiffness & Yield moment & Maximum moment & Energy \\
\hline KPJ1 & $K(\mathrm{kN} / \mathrm{rad})$ & $P_{\mathrm{y}}(\mathrm{kNm})$ & $P_{\text {max }}(\mathrm{kNm})$ & 7.35 \\
HPJ2 & 129 & 4.54 & 9.08 & 761 \\
HPJ3 & 184 & 4.54 & 12.26 & 914 \\
\hline
\end{tabular}

number of HP, HPJ2 shows 1.42 times higher initial stiffness than HPJ1. It is thought that additional length of mortise in HPJ2 give influence on rotational performance. Compression strength on the flat edge in mortise of HPJ1 is relatively lower than that of additional edge in HPJ2 on the imbedding behavior between mortise and tenon originated from rotational moment [6] [7] [9].

Comparing specimens with different number of dowels, HPJ3 shows 1.39 times higher initial stiffness, 1.35 times higher maximum moment, and 1.63 times higher yield moment than that exhibit by specimen type HPJ2.

Specimen HPJ3 with 4 pins inserted exhibit a stiffness of $255.94 \mathrm{kNm}$, a yield moment of $7.41 \mathrm{kNm}$, and a maximum moment equal to $12.26 \mathrm{kNm}$.

\section{Conclusions}

In this research, the performance for the newly developed hybrid pin (HP) joint was evaluated.

The results from the double shear test loaded in direction parallel to the grain of the base member, specimen type m3s2 exhibit stiffness equal to $1400 \mathrm{kgf} / \mathrm{mm}$, and yield strength of about $922 \mathrm{kgf}$. On the shear test with loading direction perpendicular to the grain of the base member, the specimen type m3s2 showed a stiffness of about $680 \mathrm{kgf} / \mathrm{mm}$, and a yield strength of about $840 \mathrm{kgf}$.

Mortise-tenon joint with inserted hybrid pin showed high moment-resisting-performance from the rotational tests results. These values resulted in a stiffness of $255.94 \mathrm{kNm}$, and a yield moment of $7.41 \mathrm{kNm}$ in the specimen type that includes 4 pins.

Consequently, the hybrid pin showed satisfactory performance as shear-type fastener by virtues of not only relatively high stiffness but also rich ductility originated from each different property of steel pipe and compressed wooden material.

\section{References}

[1] Burnett, D.T., Clouston, P., Damery, D. and Fissette, P. (2003) Structural Properties of Pegged Timber Connections as Affected by End Distance. Forest Products Journal, 53, 51-57.

[2] Hirai, T. (1995) Estimation of the Effect of the Length/Diameter Ratio on the Lateral Resistance of Bolted or DriftPined Timber Joint. MokuzaiGakkaishi, 41, 459-466.

[3] Jung, K., Kitamori, A., Leijten, A.J.M. and Komatsu, K. (2006) Effect of Changes in the Moisture Content Due to Surrounding Relative Humidity on the Contact Stress in Traditional Mortise and Tenon Joints 3, Pull-Out Strength of Compressed Sugikomisen Joints. MokuzaiGakkaishi, 52, 358-367. http://dx.doi.org/10.2488/jwrs.52.358

[4] Ohtani, T., Kubojima, Y. and Matsushita, K. (2005) Fracture Morphology and Effect of Compression Volume on Tensile Strength of Compressed Wood. MokuzaiGakkaishi, 51, 189-195. http://dx.doi.org/10.2488/jwrs.51.189

[5] Jung, K., Kitamori, A. and Komatsu, K. (2008) Evaluation on Structural Performance of Compressed Wood as Shear Dowel. Holzforchung, 62, 461-467. http://dx.doi.org/10.1515/HF.2008.073

[6] Jung, K., Kitamori, A. and Komatsu, K. (2009) Development of Joint System using Compressed Wooden Fastener 1, Evaluation of Pull-Out and Rotation Performance for Column and Sill Joint. Journal of Wood Science, 55, 273-282. http://dx.doi.org/10.1007/s10086-009-1027-3

[7] Jung, K., Kitamori, A. and Komatsu, K. (2010) Development of Joint System Using a Compressed Wooden Fastener 2, Evaluation of Rotation Performance for Column-Beam Joint. Journal of Wood Science, 56, 118-126. http://dx.doi.org/10.1007/s10086-009-1078-5

[8] Architectural Institute of Japan (2002) Standard for Structural Design of Timber Structure. 41-44.

[9] (2006) The Allowable Stress Design of Conventional Post And Beam Structures. Japan Howsing and Wood Technology Center, 57. 